\title{
Estudo comparativo das espécies de Candida: sensibilidade antifúngica e genes de virulência
}

\section{Comparative study of Candida species: antifungal susceptibility and virulence genes}

Estudio comparativo de las especies de Candida: sensibilidad antifúngica y genes de virulência

\author{
Camila Aoyama Vieira ${ }^{1}$ \\ Wérika Weryanne Rosa de Souza ${ }^{2}$ \\ Janaína Sousa de Lima \\ Letícia Silveira Goulart ${ }^{4}$
}

${ }^{1}$ Graduanda de Enfermagem. Bolsista de Iniciação Científica do CNPq, da Universidade Federal do Mato Grosso (UFMT), Campus de Rondonópolis E-mail: japah_10@hotmail.com

${ }^{2}$ Graduanda de Enfermagem. Bolsista de Iniciação Científica do CNPq da Universidade Federal do Mato Grosso (UFMT), Campus de Rondonópolis.

E-mail:wwrsouza@gmail.com

${ }^{3}$ Graduanda de Enfermagem. Bolsista de Iniciação Científica do CNPq, da Universidade Federal do Mato Grosso (UFMT), Campus de Rondonópolis.

E-mail: janainalima62@hotmail.com

${ }^{4}$ Doutora em Biologia Celular e Molecular, Professora do curso de Enfermagem na Universidade Federal de Mato Grosso (UFMT), Campus de Rondonópolis. E-mail: Igoulart77@yahoo.com.br 
Resumo: O objetivo deste estudo foi comparar a sensibilidade antifúngica e a presença dos genes de virulência SAP1-3 em linhagens de Candida spp. Foram estudados 49 isolados, sendo 30 C. albicans e 19 Candida não-albicans (CNA). A determinação do perfil de sensibilidade foi realizada conforme protocolo do Clinical and Laboratory Standards Institute. Para identificação dos genes SAP1-3, foi utilizado método de PCR. Todas as amostras de $C$. albicans foram sensíveis ao fluconazol, dentre as CNA 21\% foram sensíveis e 68,4\% foram SDD, $100 \%$ das linhagens de C. albicans e 94,7\% de CNA foram sensíveis ao cetoconazol. Para itraconazol, $86,7 \%$ dos isolados de C. albicans e 42,1\% de CNA foram sensíveis. Os genes mais frequentes nas linhagens de $C$. albicans foram SAP1 $(56,6 \%$,) e SAP2 (40\%) seguido de SAP3 (26\%). As amostras de CNA apresentaram um predomínio de SAP2 (42,1\%), seguido por SAP1 (10,5\%), SAP3 não foi identificado. As espécies de Candida apresentam diferenças significativas quanto ao perfil de sensibilidade a azólico e em relação à presença dos genes SAP1-3, sugerindo que esses fatores devem refletir em uma terapêutica e patogênese distintas para estas leveduras.

Palavras-chave: Candida; sensibilidade antifúngica; Aspartil Proteases Secretórias.

\begin{abstract}
The aim of this study was to compare the antifungal susceptibility and the presence of the SAP1-3 virulence genes in Candida spp. It was studied 49 isolates, being 30 C. albicans and 19 Candida non-albicans (NCA). The determination of the susceptibility profile was performed according to the protocol of the Clinical and Laboratory Standards Institute. PCR method was used to identify the SAP1-3 genes. All C. albicans samples were sensitive to fluconazole, between that NCA $21 \%$ were sensitive and $68.4 \%$ were SDD. 100\% C. albicans and 94.7\% NCA were sensitive to ketoconazole. For itraconazole, $86.7 \%$ of $C$. albicans strains and $42.1 \%$ of NCA were sensitive. The most frequent genes in the $C$. albicans strains were SAP1 (56.6\%) and SAP2 (40\%) followed by SAP3 (26\%). CNA samples showed a predominance of SAP2 (42.1\%), followed by SAP1 (10.5\%), SAP3 was not identified. Candida species present significant differences in the sensitivity profile to azole and in relation to the presence of the SAP1-3 genes, suggesting that these factors should reflect in a different therapeutics and pathogenesis for these yeasts.
\end{abstract}

Keywords: Candida; antifungal susceptibility; Secreted Aspartyl Proteinase.

Resumén: El objetivo de este estudio fue comparar la sensibilidad antifúngica y la presencia de los genes de virulencia SAP1-3 en linajes de Candida spp. Se estudiaron 49 aislados, siendo 30 C. albicans y 19 Candida no albicans (CNA). La determinación del perfil de sensibilidad se llevó a cabo de acuerdo con el protocolo del Clinical and Laboratory Standards Institute. Para la identificación de los genes SAP1-3 se utilizó el método de PCR. Todas las muestras de C. albicans fueron sensibles al fluconazol, entre las CNA 21\% fueron sensibles y el 68,4\% fueron SDD, el $100 \%$ de los linajes de C. albicans y el $94,7 \%$ de CNA fueron sensibles al ketoconazol. Para itraconazol, el $86,7 \%$ de los aislados de C. albicans y el $42,1 \%$ de CNA fueron sensibles. Los genes más frecuentes en los linajes de C. albicans fueron $\operatorname{SAP} 1$ (56,6\%, y SAP2 (40\%) seguido de SAP3 (26\%). Las muestras de CNA presentaron un predominio de SAP2 (42,1\%), seguido por SAP1 (10,5\%), SAP3 no fue identificado. Las especies de Candida presentan diferencias significativas en cuanto al perfil de sensibilidad a la azucación y en relación a la presencia de los genes SAP1-3, sugiriendo que estos factores deben reflejar en una terapéutica y patogénesis distintas para estas levaduras.

Palabras clave: Candida; sensibilidad antifúngica; Aspartil Proteasas Secrecion. 


\section{INTRODUÇÃO}

A candidíase é uma micose oportunista causada por leveduras do gênero Candida, podendo estar associada a quadros de infecções superficiais e fungemias. Esses micro-organismos colonizam a mucosa oral, vaginal e trato gastrointestinal, porém, diante de fatores predisponentes tornam-se patogênicos. Os fatores predisponentes para candidíase compreendem linfócitos $\mathrm{T}-\mathrm{CD}_{4}$ abaixo de 200 células $/ \mathrm{mm}^{3}$, tabagismo, uso de terapia imunossupressora e antibióticos de amplo espectro, procedimentos cirúrgicos, extremos de idade ( $<1$ ano e idade avançada) e diabetes mellitus.

Candida albicans é a espécie mais frequentemente encontrada em amostras clínicas, correspondendo a 70-80\% dos isolados, prevalente em infecções superficiais e invasivas. Todavia espécies não-albicans têm surgido como importantes patógenos oportunistas, com predomínio de Candida glabrata, Candida parapsilosis, Candida tropicalis e Candida krusei. Os antifúngicos azólicos são comumente usados no tratamento da candidíase, entretanto diferenças na suscetibilidade de Candida albicans e Candida não-albicans (CNA) têm sido relatadas.

Diversos fatores de virulência contribuem para a colonização e infecção por espécies de Candida, dentre estes, destacam-se as enzimas hidrolíticas Aspartil Proteases Secretórias (Secreted Aspartyl Proteinases - SAP). Os genes SAP1-3 desempenham funções importantes na patogênese da candidíase e estão relacionados a uma maior habilidade dos microrganismos em colonizar e penetrar os tecidos do hospedeiro. Esses genes estão envolvidos na adesão de $C$. albicans às células hospedeiras, crescimento em meio contendo proteínas, capacidade de decompor proteínas na saliva e evasão do sistema imunológico, contribuindo, assim, para a disseminação da levedura através da corrente sanguínea.

Todas as espécies de Candida secretam enzimas hidrolíticas, entretanto, apesar de haver extensas pesquisas para identificar atributos patogênicos em C. albicans, os fatores de virulência em espécies não-albicans são menos conhecidos, e estas espécies, aparentemente, expressam fatores de virulência em um nível mais baixo quando comparado com C. albicans. Nesse contexto, o objetivo do presente estudo foi comparar a sensibilidade antifúngica e a presença de genes de virulência SAP1-3 entre C. albicans e Candida não-albicans. 


\section{METODOLOGIA}

\subsection{Micro-organismos estudados}

Foram estudados 49 isolados orais de Candida spp., sendo $30 \mathrm{C}$. albicans e 19 Candida não-albicans, destas, 13 são C. glabrata, 4 C. tropicallis e 2 C. krusei . As leveduras foram obtidas através da coleta de swabs estéreis da mucosa oral de pacientes HIV-positivo acompanhados no Serviço de Atendimento Especializado (SAE) do município de Rondonópolis, MT. Os participantes foram recrutados em uma amostra de conveniência no período de janeiro a maio de 2015, durante suas consultas de rotina no serviço de saúde, sendo informados sobre os objetivos, riscos e benefícios do estudo e assinaram um termo de consentimento livre e esclarecido. O estudo foi aprovado pelo Comitê de Ética em Pesquisa do Hospital Universitário Júlio Muller/UFMT, número: 31905114.6.0000.5541.

Os swabs foram cultivados em ágar Sabouraud dextrose (Difco, Detroit, EUA), suplementado com cloranfenicol (100 $\mu \mathrm{g} / \mathrm{mL}$ ) e em ágar cromogênico CHROMagar Candida (PROBAC, São Paulo, Brasil), incubados a $37^{\circ} \mathrm{C}$ por 4872 h. A identificação específica das espécies de Candida foi realizada através do método de PCR (Reação em Cadeia da Polimerase) espécie-específica baseada no protocolo previamente descrito por Liguori et al. (2010). A PCR foi realizada em um volume de reação total de $25 \mu \mathrm{L}$, constituído por 20 ng de DNA, Taq Buffer 10x, dNTPs 10 mM, 0,8 $\mathrm{LL}$ de cada primer (20pmol/ $\mu \mathrm{L}$ ) e Taq DNA polimerase 1,25 U. As condições para a amplificação foram: desnaturação inicial $\left(92^{\circ} \mathrm{C}, 2 \mathrm{~min}\right) ; 35$ ciclos de desnaturação $\left(95^{\circ} \mathrm{C}, 1 \mathrm{~min}\right)$, anelamento $\left(50^{\circ} \mathrm{C}, 1 \mathrm{~min}\right)$, extensão $\left(72^{\circ} \mathrm{C}, 1 \mathrm{~min}\right)$ e extensão final $\left(72^{\circ} \mathrm{C}\right.$, $10 \mathrm{~min})$.

\subsection{Testes de sensibilidade a antifúngicos}

Foi realizada a técnica de microdiluição em caldo conforme o protocolo M-27A3 do Clinical and Laboratory Standards Institute (CLSI). Utilizouse inóculo com uma concentração final de $1,5 \times 10^{3}$ células $/ \mathrm{mL}$ em meio RPMI- 1640 (Sigma chemical Co., USA) tamponado a pH 7,0 com 0,165 de ácido $\mathrm{M}$ morpholinepropanesulfonic (MOPS) (Sigma), e incubação a $35^{\circ} \mathrm{C}$ 
por 24-48h. Os antifúngicos testados foram fluconazol nas concentrações de 0,125 a $64 \mu \mathrm{g} / \mathrm{mL}$, itraconazol e cetoconazol com concentrações que variaram de 0,03 a $16 \mu \mathrm{g} / \mathrm{mL}$.

Com base nas diretrizes do documento M27-S4 do CLSI (2012), os valores de corte epidemiológico para fluconazol em C. albicans e C. tropicalis são: $\mathrm{CIM} \leq 2 \mu \mathrm{g} / \mathrm{mL}$ são considerados sensível, $\geq 8 \mu \mathrm{g} / \mathrm{mL}$ resistente e $4 \mu \mathrm{g} /$ $\mathrm{mL}$ sensivel dose dependente (SDD); para C. glabrata, $\mathrm{CIM} \leq 32 \mu \mathrm{g} / \mathrm{mL}$ são $\mathrm{SDD}$ e $\geq 64 \mu \mathrm{g} / \mathrm{mL}$ resistente, os isolados de C. krusei são considerados intrinsecamente resistentes a o fluconazol, e seus CIMs não devem ser interpretados usando essa escala. Para o itraconazol, os valores de referência em espécies de Candida são CIM $\leq 0,125 \mu \mathrm{g} / \mathrm{mL}$ sensível, $\geq 1 \mu \mathrm{g} / \mathrm{mL}$ resistente e 0,25-0,5 $\mu \mathrm{g} / \mathrm{mL} \mathrm{SDD} \mathrm{(CLSI,} \mathrm{2008).} \mathrm{Os} \mathrm{valores} \mathrm{de} \mathrm{referência} \mathrm{para} \mathrm{o} \mathrm{cetoco-}$ nazol não são descritos pelo CLSI, assim, adotou-se o parâmetro proposto por Mulu et al. (2013), que consideram resistente $\geq 4 \mu \mathrm{g} / \mathrm{mL}$.

\subsection{Identificação dos genes SAP1-3}

Para identificação dos genes SAP1-3, foram realizados ensaios de PCR, sendo utilizado PCR multiplex para os genes SAP1 e SAP3. As reações de amplificação e os oligonucleotídeos utilizados foram como reportado por Bassyouni et al. (2015), com algumas modificações. As reações foram realizadas em um volume final de $25 \mu \mathrm{L}$, contendo 20 ng de DNA, $12,5 \mu \mathrm{L}$ de GoTaq Hot Start Green Master Mix e 0,75 $\mu \mathrm{L}$ (20 pmol/ $\mu \mathrm{L}$ ) de cada primer específico. As condições de amplificação foram como segue: desnaturação inicial ( $\left.94^{\circ} \mathrm{C}, 3 \mathrm{~min}\right) ; 30$ ciclos de desnaturação $\left(94^{\circ} \mathrm{C}, 30 \mathrm{seg}\right)$, anelamento $\left(46^{\circ} \mathrm{C}\right.$, $\left.30 \mathrm{seg}\right)$, extensão $\left(72^{\circ} \mathrm{C}, 30 \mathrm{seg}\right.$ ) e extensão final $\left(72^{\circ} \mathrm{C}, 10 \mathrm{~min}\right)$. Para o gene $S A P 2$, a temperatura de anelamento utilizada foi de $52^{\circ} \mathrm{C}$. A tabela 1 apresenta as sequências dos oligonucleotídeos utilizados neste estudo. 
Tabela 1 - Sequência dos oligonucleotídeos utilizados nos ensaios de PCR para identificação dos genes SAP

\begin{tabular}{ccc}
\hline Primer & Sequência & $\begin{array}{c}\text { Produto } \\
\mathbf{( p b )}\end{array}$ \\
\hline CA & 5'-TCAACTTGTCACAGATTATT-3' & 402 \\
CGLA & 5'-CACGACTCGACACTTTCTAATT-3' & 632 \\
CT & 5'-AAGAATTTAACGTGGAAACTTA-3' & 149 \\
CK & 5'-GATTTAGTACTACACTGCGTCA-3' $^{\prime}$ & 475 \\
ITS4 & 5'- TCC TCCGCT TAT TGA TAT GC-3' & 0 \\
SAP1 & Forward 5'-TCA ATC AAT TTA CTC TTC CAT TTC TAA CA-3' & 161 \\
& Reverse 5'-CCA GTA GCA TTA ACA GGA GTT TTA ATG ACA-3' & \\
SAP2 & Forward 5'-AAC AAC AAC CCA CTA GAC ATC ACC-3' & 178 \\
& Reverse 5'-TGA CCA TTA GTA ACT GGG AAT GCT TTA GGA-3' & \\
SAP3 & Forward 5'-CCT TCT CTA AAA TTA TGG ATT GGA AC-3' & 231 \\
& Reverse 5'-TTG ATT TCA CCT TGG GGA CCA GTA ACA TTT-3' & \\
\hline
\end{tabular}

\subsection{Análise estatística}

Os dados foram tabulados em programa Excel 2010 (Microsoft Office) e analisados pelo programa Epi Info 7.2.0.1; aplicou-se o Teste de MannWhitney para os dados não paramétricos. As variáveis categóricas foram comparadas usando o teste de Qui-quadrado ou Exato de Fisher conforme mais apropriado. Adotou-se um nível de significância de 5\%.

\section{RESULTADOS}

Os testes de suscetibilidade de C. albicans para o fluconazol revelaram que os valores de CIM variaram de 0,125 a 0,5 $\mathrm{\mu g} / \mathrm{mL}$, para o itraconazol de 0,03 a $0,5 \mu \mathrm{g} / \mathrm{mL}$ e para o cetoconazol foi de $0,03 \mu \mathrm{g} / \mathrm{mL}$. O perfil de sensibilidade antifúngica em CNA demonstrou que para o fluconazol a CIM apresentou valores entre 0,125 a $4 \mu \mathrm{g} / \mathrm{mL}$, para o itraconazol de 0,03-16 $\mu \mathrm{g} / \mathrm{mL}$ e para o cetoconazol de 0,03 a16 $\mu \mathrm{g} / \mathrm{mL}$.

Todas as amostras de $C$. albicans foram sensíveis ao fluconazol, dentre as CNA 23,5\% foram sensíveis e 76,5\% foram classificadas como SDD, $100 \%$ das linhagens de C. albicans e $94,7 \%$ de CNA foram sensíveis ao cetoconazol. Os ensaios para o itraconazol demonstraram que $86,7 \%$ dos isolados de C. albicans e 42,1\% de CNA foram sensíveis a este azólico (Tabela 2). Observamos uma diferença estatística ao compararmos os valores de CIM 
entre C. albicans e CNA para o fluconazol $(p=0,001)$, itraconazol $(p=0,001)$ e cetoconazol $(p=0,003)$.

Tabela 2 - Perfil de suscetibilidade antifúngica de linhagens clínicas de $C$. albicans e Candida não-albicans

\begin{tabular}{ccccc}
\hline Espécie & Antifúngico & $\begin{array}{c}\text { Amostra S } \\
\mathbf{n}(\%)\end{array}$ & $\begin{array}{c}\text { Amostra SDD } \\
\mathbf{n}(\%)\end{array}$ & $\begin{array}{c}\text { Amostra R } \\
\mathbf{n}(\%)\end{array}$ \\
\hline \multirow{2}{*}{$\begin{array}{c}\text { C. albicans } \\
(\mathrm{n}=30)\end{array}$} & Fluconazol & $30(100)$ & $0(0)$ & $0(0)$ \\
& Cetoconazol & $30(100)$ & $0(0)$ & $0(0)$ \\
& Itraconazol & $26(86,7)$ & $4(13,3)$ & $0(0)$ \\
\hline \multirow{2}{*}{ CNA $(\mathrm{n}=19)$} & Fluconazol* & $4(23,5)$ & $13(76,5)$ & $0(0)$ \\
& Cetoconazol & $18(94,7)$ & $0(0)$ & $1(5,3)$ \\
& Itraconazol & $8(42,1)$ & $8(42,1)$ & $3(15,8)$ \\
\hline
\end{tabular}

* Os isolados de C. krusei não estão inseridos no resultado dos testes para o fluconazol, pois, de acordo com o CLSI, são considerados intrinsecamente resistentes a este antifúngico. S: Sensível; SDD: Sensível Dose-Dependente; R: Resistente. CNA: Candida não-albicans.

Os ensaios de PCR permitiram identificar a presença dos genes SAP13 em 24 (80\%) isolados clínicos de C. albicans e dos genes SAP1-2 em 10 $(52,6 \%)$ amostras de CNA. Os genes mais frequentes nas linhagens de $C$. albicans foram SAP1 $(56,6 \%, n=17)$ e SAP2 $(40 \%, n=12)$. SAP3 foi identificado em apenas $26 \%(n=8)$ dos isolados. As linhagens de C. albicans apresentaram diferentes padrões genotípicos (Tabela 3). As figuras 1 e 2 apresentam os produtos de amplificação dos genes SAP1-3 e SAP2, respectivamente.

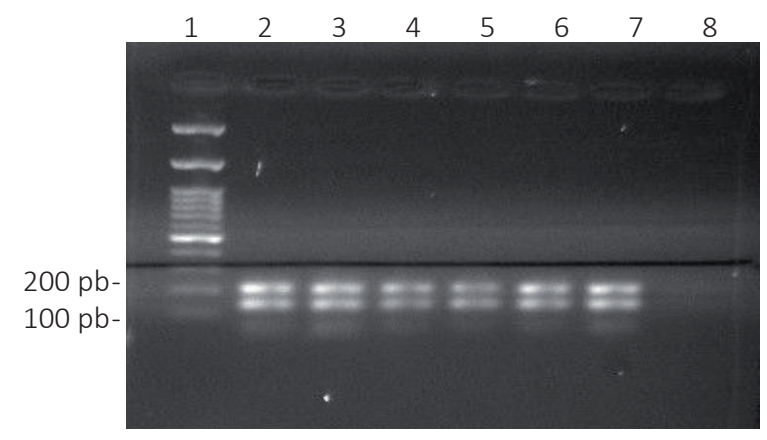

Figura 1 - Amplificação dos genes SAP1 e SAP3 por PCR. SAP1 amplicon de $161 \mathrm{pb}$. SAP3 amplicon de $231 \mathrm{pb}$. Linha 1: Marcador de peso molecular de 100pb, Linha 2: Controle positivo C. albicans ATCC32354, Linhas 3-7: isolados de C. albicans, Linha 8: controle negativo. 


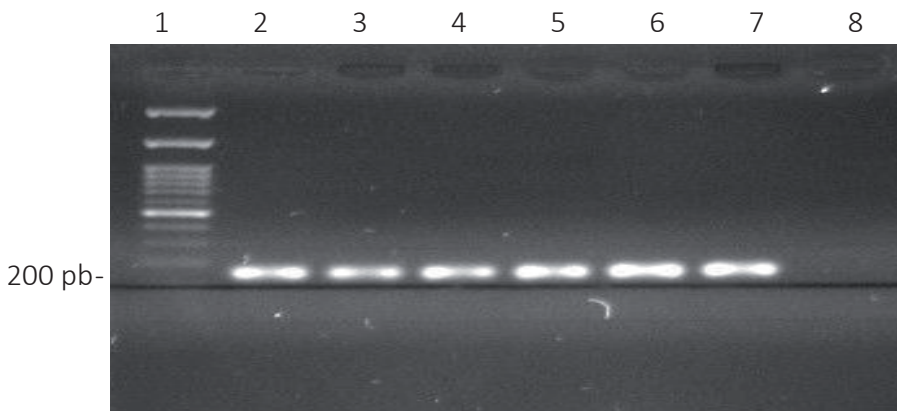

Figura 2 - Amplificação do gene SAP2 por PCR. Amplicon de 178 pb. Linha 1: Marcador de peso molecular de 100pb, Linha 2: Controle positivo C. albicans ATCC32354, Linhas 3-7: isolados de C. albicans, Linha 8: controle negativo.

A análise genotípica das espécies de CNA evidenciou um predomínio do gene SAP2 $(42,1 \%, n=8)$, seguido por SAP1 $(10,5 \%, n=2)$. O gene SAP3 não foi identificado nestas espécies, e nenhum destes isolados apresentou mais de um gene. Os resultados da análise estatística indicaram uma diferença significativa na frequência dos genes SAP1 $(p=0,001), \operatorname{SAP2}(p=0,023)$ e SAP3 $(p=0,013)$ entre C. albicans e CNA.

Tabela 3 - Padrão genotípico identificado em linhagens de C. albicans

\begin{tabular}{ccc}
\hline Padrão & Genótipo & $\mathbf{n}(\mathbf{\%})$ \\
\hline $\mathbf{1 .}$ & SAP1/SAP2 & $7(23,3)$ \\
$\mathbf{2}$. & SAP1/SAP3 & $4(13,3)$ \\
$\mathbf{3 .}$ & SAP2/SAP3 & $2(6,6)$ \\
$\mathbf{4 .}$ & SAP1 & $6(20)$ \\
$\mathbf{5 .}$ & SAP2 & $3(10)$ \\
$\mathbf{6 .}$ & SAP3 & $2(6,6)$ \\
\hline
\end{tabular}

\section{DISCUSSÃO}

As espécies de Candida exibem ampla variedade na suscetibilidade à maioria dos antifúngicos utilizados na clínica médica. Por exemplo, $C$. krusei é intrinsecamente resistente ao fluconazol, com uma taxa global de $78,3 \%$, enquanto que C. glabrata manifestam menor suscetibilidade comparada a outras espécies de Candida, com uma taxa global de resistência de 15,7\% (SANGUINETTI; POSTERARO; LASS-FLÖRL, 2015). Neste estudo, 
os resultados dos testes de sensibilidade frente aos antifúngicos azólicos evidenciaram uma maior suscetibilidade entre as amostras de C. albicans, sendo que todas foram sensíveis ao fluconazol e ao cetoconazol e 86,7\% ao itraconazol. A maioria (68\%) das linhagens de CNA foi classificada como SDD para o fluconazol e sensíveis $(94,7 \%)$ ao cetoconazol. Os ensaios de suscetibilidade ao itraconazol para CNA revelaram que $42,1 \%$ dos isolados foram sensíveis e 42\% SDD.

Estudos prévios realizados na China (LI et al., 2013), no Brasil (TERÇAS et al., 2017; FAVALESSA; MARTINS; HAHN, 2010) e na Índia (DAR; SREEDAR; SHUKLA, 2015) também evidenciaram uma maior sensibilidade de amostras clínicas de $C$. albicans aos antifúngicos quando comparadas às espécies não-albicans. Paula et al. (2015) pesquisaram a suscetibilidade à antifúngicos em isolados orais de Candida spp. de pacientes HIV-positivo e verificaram que $65 \%$ de suas amostras de $C$. albicans foram sensíveis ao fluconazol, enquanto que, para os isolados de CNA, a suscetibilidade a este azólico foi de $45,5 \%$. Linhagens de C. albicans isoladas do tubo endotraqueal de pacientes internados em uma unidade de terapia intensiva do Irã apresentaram uma maior suscetibilidade $(64,8 \%)$ ao fluconazol do que os isolados de CNA (40,9\%) (BAGHDADI et al., 2016). Na Coréia, Song et al. (2015) estudaram a sensibilidade antifúngica em leveduras orais e constataram que todas as linhagens de $C$. albicans foram sensíveis ao fluconazol e ao itraconazol, enquanto que, $37,5 \%$ das amostras de CNA foram classificadas como sensíveis ao fluconazol e $25 \%$ ao itraconazol.

Um inquérito epidemiológico realizado no estado de Mato Grosso, com amostras de Candida spp. isoladas de mulheres assintomáticas e sintomáticas para candidíase vaginal evidenciou que 93,1\% de C.albicans e apenas 27,6\% de CNA foram sensíveis ao fluconazol (GOULART et al., 2016). Satana, Genc e Erturan (2010) estudaram isolados de Candida spp. da mucosa oral de pacientes HIV-positivo da Turquia e detectaram que 92\% de linhagens de C.albicans foram suscetíveis ao cetoconazol, diferente das amostras de CNA em que 72,2\% foram classificados como sensíveis. Mondal et al. (2013) observaram que a maioria (81,5\%) das linhagens de C. albicans foram sensíveis ao cetoconazol, sendo que, para este mesmo antifúngico, a suscetibilidade para CNA foi de $68 \%$. 
Os genes SAP são reconhecidos por desempenharem um papel importante na patogenicidade de $C$. albicans; estes são agrupados em 6 subgrupos, SAP1-SAP3, SAP4-SAP6, SAP7, SAP8, SAP9 e SAP10 cada um caracterizado por uma estreita homologia e relevância fisiológica. As proteínas codificadas por estes genes são importantes fatores de virulência, pois fornecem um sistema proteolítico vital tanto para o comensalismo quanto para o desenvolvimento de infecções, permitindo a aquisição de nutrientes pela proteólise de substratos do hospedeiro (AOKI et al., 2011; CHAFFIN, 2008; KUMAR et al., 2015; PERICOLINI et al., 2015;).

No presente estudo, o gene SAP1 foi o mais frequente $(56,6 \%)$ entre as amostras de C. albicans. Resultado semelhante foi encontrado por Modrzewska, Kurnatowski e Khalid (2016) ao identificar, por PCR, que SAP1 predominou (54,5\%) em isolados orais de Candida spp. Segundo os autores, a presença dos genes varia de acordo com a espécie, e SAP1-3 predominaram em indivíduos com doença periodontal quando comparado ao grupo controle e aos pacientes oncológicos. Diferentemente de nossos dados, uma pesquisa genotípica para SAP1-10 com isolados vaginais de $C$. albicans revelou uma frequência de $94 \%$ para SAP1, 98\% para SAP2 e $80 \%$ para SAP3. A análise da expressão destes genes por RT-PCR em tempo real utilizando um Epitélio Vaginal Humano Reconstituído (EVHR) indicou que 90\% de C. albicans expressaram os genes SAP1-3, sugerindo que as proteínas sap desenvolvam uma importante função na patogênese da infecção (MONROY-PEREZ et al. , 2013).

A aspartil protease mais abundantemente expressa in vitro é a codificada pelo gene SAP2, conhecida por sua capacidade de decompor proteínas na saliva, albumina, queratina e hemoglobina humanas, destruindo a barreira protetora do hospedeiro por degradação de proteínas e, como consequência, contribui para a colonização e posterior penetração profunda nos tecidos do hospedeiro (BASSYOUNI et al., 2015; CHEN et al., 2012; COPPING et al., 2005). Através da análise genotípica das amostras de CNA, identificamos que SAP2 foi o gene mais prevalente $(42,1 \%$, ) nestas espécies. Bassyouni et al. (2015) investigaram o perfil genético de Candida spp. isoladas de mulheres diabéticas e não-diabéticas com candidíase vulvovaginal, revelando que os genes SAP1 e SAP2 foram os mais frequentes em ambos 
os grupos, e que SAP1-2 foi identificado em 100\% dos isolados do grupo não diabético e em $97,5 \%$ do grupo diabético.

O gene SAP3 foi identificado em $26 \%$ das amostras de C. albicans e não foi encontrado em nenhum isolado de CNA. Estudos anteriores comprovam que, durante a infecção vaginal, há uma maior expressão dos genes SAP1, SAP3 e SAP8 diferente do que acontece na infecção oral, havendo uma baixa expressão destas enzimas (NAGLIK; CHALLACOMBE; HUBE, 2003; NAGLIK et al., 2008). Alves et al. (2014) caracterizaram a expressão de genes de virulência em C. albicans e C. glabrata utilizando um modelo de EVHR, e destacaram que o gene SAP3 foi expresso em quantidade mínima, e em alguns casos, ausente em ambas as espécies.

Nosso estudo revelou uma diferença significativa ao compararmos a frequência dos genes SAP1-3 entre C. albicans e não-albicans. Segundo Haynes, (2001) a identificação de fatores de virulência exclusivos de uma espécie particular de Candida pode prover informações importantes do processo patogênico, sendo provável que diferentes espécies compartilhem determinados fatores de virulência, podendo também apresentar características distintas, sendo importante identificar quais fatores as espécies possuem em comum e quais são exclusivos.

\section{CONCLUSÃO}

As linhagens de Candida albicans e CNA apresentaram uma diferença estatística para a sensibilidade ao fluconazol, cetoconazol e itraconazol, indicando a necessidade da realização de uma terapêutica antifúngica direcionada para cada espécie. A análise do perfil genotípico para SAP1-3 indicou distintos padrões entre Candida albicans e CNA, refletindo em uma provável diferença na patogênese das infecções causadas por essas leveduras, sobretudo, em uma maior virulência de C. albicans. Os resultados apontam para a necessidade de se estudar os outros genes membros da família SAP, além da realização de ensaios expressão gênica que busquem confirmar as diferenças desses genes in vivo. 


\section{REFERÊNCIAS}

ALVES, C. T. et al. Candida albicans promotes invasion and colonisation of Candida glabrata in a reconstituted human vaginal epithelium. Journal of Infection, v. 69, n. 4, p. 396-407, 2014. DOI: http://dx.doi.org/10.1016/j.jinf.2014.06.002

AOKI, W. et al. Comprehensive characterization of secreted aspartic proteases encoded by a virulence gene family in Candida albicans. The Journal of Biochemistry, v. 150, p. 431-8, 2011. DOI: http://dx.doi.org/10.1093/jb/mvr073.

BAGHDADI, E. et al. Antifungal susceptibility patterns of candida species recovered from endotracheal tube in an intensive care unit. Advances in Medicine, v. 6, 2016. DOI: http://dx.doi.org/10.1155/2016/9242031

BASSYOUNI, R. H. et al. Phospholipase and aspartyl proteinase activities of candida species causing vulvovaginal candidiasis in patients with type 2 diabetes mellitus. Journal of Microbiology and Biotechnology, v. 25, n. 10, article A021, p. 1734-41, 2015. DOI: http://dx.doi.org/10.4014/jmb.1504.04009

CHAFFIN, W. L. Candida albicans cell wall proteins. Microbiology and Molecular Biology Reviews, v. 72, N. 3, p. 495-544, 2008. DOI: http://dx.doi.org/10.1128/ MMBR.00032-07.

CHEN, Y. et al. Rhb1 regulates the expression of secreted aspartic protease 2 through the TOR signaling pathway in Candida albicans. Eukaryotic Cell, v. 11, n. 2, p. 168-82, 2012. DOI:10.1128/EC.05200-11

CLINICAL AND LABORATORY STANDARDS INSTITUTE (CLSI). Reference method for broth dilution antifungal susceptibility testing of yeasts; fourth informational supplement. Wayne: Clinical and Laboratory Standards Institute, 2012. (Document M27-S4).

. Reference method for broth dilution antifungal susceptibility testing of yeasts; Approved standard. 3. ed. Wayne: Clinical and Laboratory Standards Institute, abr. 2008. (Document M27-A3)

COPPING, V. M. S. et al. Exposure of Candida albicans to antifungal agents affects expression of SAP2 and SAP9 secreted proteinase genes. Journal of Antimicrobial Chemotherapy, v. 55, n. 5, p. 645-54, 2005. DOI:10.1093/jac/dki088

DAR, M.S.; SREEDAR, G.; SHUKLA, A. An in vitro study of antifungal drug susceptibility of Candida species isolated from human immunodeficiency virus seropositive and human immunodeficiency virus seronegativeindividuals in Lucknow population Uttar Pradesh. Journal of Oral Maxillofacial Pathology, v. 19, p. 205-11, 2015. DOI: 10.4103/0973029X.164534 
FAVALESSA, O. C.; MARTINS, M. A.; HAHN, R. C. Aspectos micológicos e suscetibilidade in vitro de leveduras do gênero Candida em pacientes HIV-positivos provenientes do Estado de Mato Grosso. Sociedade Brasileira de Medicina Tropical, v. 43, n. 6, p. 673-7, nov./dez. 2010. DOI: http://dx.doi.org/10.1590/ S0037-86822010000600014

GOULART, L. S. et al. Species distribution and antifungal susceptibility to vulvovaginal Candida spp. in Southern Mato Grosso State, Brazil. Jornal Brasileiro de Patologia e Medicina Laboratorial, Rio de Janeiro, v. 52, n. 4, p. 233-7, jul./ago. 2016. DOI: http://dx.doi.org/10.5935/1676-2444.20160039

HAYNES, K. Virulence in Candida species. Trends Microbiology, v. 9, n. 12, p. 59196, 2001. DOI: https://doi.org/10.1016/S0966-842X(01)02237-5

KUMAR, R.; SARASWAT, D.; TATI, S.; EDGERTON, M. Novel aggregation properties of Candida albicans secreted aspartyl proteinase Sap6 mediate virulence in oral candidiasis. Infection and Imunnity v. 83, n. 7, p. 2614-26, 2015. DOI:10.1128/ IAl.00282-15.

LI, Y-Y. et al. Asymptomatic oral yeast carriage and antifungal susceptibility profile of HIV-infected patients in Kunming, Yunnan Province of China. BMC Infectious Diseases, v. 13, n. 46, 2013. DOI: http://www.biomedcentral. com/1471-2334/13/46

LIGUORI, G. et al. Candida albicans identification: comparison among nine phenotypic systems and a multiplex PCR. Journal of Preventive Medicine and Hygiene, v. 51, n. 3, p. 121-4, 2010. DOI: http://dx.doi.org/10.15167/2421-4248/ jpmh2010.51.3.225

MODRZEWSKA, B.; KURNATOWSKI, P.; KHALID, K. Comparison of proteolytic activity of Candida sp. strains depending on their origin. Journal de Mycologie Médicale, v. 26, n. 2, p. 138-47, 2016. DOI: http://dx.doi.org/10.1016/j.mycmed.2016.01.005

MONDAL, $S$. et al. Species distribution and in vitro antifungal susceptibility patterns of Candida. Journal of Institute of Medicine, v. 35, n. 1, abr. 2013.

MONROY-PÉREZ, E. et al. SAP Expression in Candida albicans Strains Isolated from Mexican Patients with Vaginal Candidosis. International Journal of Clinical Medicine, v. 4, n. 1, p. 25-31, 2013. DOI: http://dx.doi.org/10.4236/ijcm.2013.41006

MULU, A. et al. Frequent detection of 'azole' resistant Candida species among late presenting AIDS patients in northwest Ethiopia. BMC Infectious Diseases, v. 13, n. 82, 2013. DOI: 10.1186/1471-2334-13-82.

NAGLIK, J. R.; CHALLACOMBE, S. J.; HUBE, B. Candida albicans secreted aspartyl proteinases in virulence and pathogenesis. Microbiology and Molecular Biology Reviews, v. 67, n. 3, p. 400-28, 2003. DOI: 10.1128/MMBR.67.3.400-428.2003 
NAGLIK, J. R.; MOYES, D.; MAKWANA, J.; KANZARIA, P. et al. Quantitative expression of the Candida albicans secreted aspartyl proteinase gene family in human oral and vaginal candidiasis. Microbiology, v. 154, n. 11, p. 3266-80, 2008. DOI: 10.1099/ mic.0.2008/022293-0

PAULA, S. B. et al. Oral Candida colonization in HIV-infected patients in LondrinaPR, Brazil: antifungal susceptibility and virulence factors. Journal of Infection in Developing Countries, v. 9, n. 12, p. 1350-9, 2015. DOI: 10.3855/jidc.6970

PERICOLINI, E. et al. Secretory aspartyl proteinases cause vaginitis and can mediate vaginitis caused by Candida albicans in mice. mBio, v. 6, n. 3, e00724-15, 2015. DOI:10.1128/mBio.00724-15.

SANGUINETTI, M.; POSTERARO, B.; LASS-FLÖRL, C. Antifungal drug resistance among Candida species: mechanisms and clinical impact. Mycoses, v. 58, n. 2, p. 2-13,2015. DOI: 10.1111/myc.12330.

SATANA, D.; GENC, G. E.; ERTURAN, Z. The antifungal susceptibilities of oral Candida spp isolates from HIV-infected patients. African Journal Microbiol Research, v. 4, n. 6, p. 466-70, 2010. ISSN: 1996-0808.

SONG, Y. B.; SUH, M. S.; HA, G. Y.; KIM, H. Antifungal susceptibility testing with etest for Candida species isolated from patients with oral candidiasis. Annals of Dermatology, v. 27, n. 6, p. 715-20, 2015. DOI: http://dx.doi.org/10.5021/ ad.2015.27.6.715

TERÇAS, A. L. G. et. al. Antifungal drug susceptibility of candida species isolated from HIV-positive patients recruited at a public hospital in São Luís, Maranhão, Brazil. Frontiers in Microbiology, v. 8, n. 298, 2017. DOI: 10.3389/fmicb.2017.00298 